\title{
Salvianolic Acid B Attenuates Apoptosis of HUVEC Cells Treated with High Glucose or High Fat via Sirt1 Activation
}

\author{
Jinghui Zhai, Lina Tao $(\mathbb{D}$, Yueming Zhang $(\mathbb{D}$, Huan Gao, Xiaoyu Qu, \\ Yanqing Song $\mathbb{D}$, and Sixi Zhang \\ Department of Pharmacy, The First Hospital of Jilin University, Changchun 130021, China \\ Correspondence should be addressed to Yanqing Song; songyanq@126.com and Sixi Zhang; zhsixi@163.com
}

Received 22 October 2018; Revised 13 February 2019; Accepted 7 April 2019; Published 21 April 2019

Academic Editor: Miguel Vilas-Boas

Copyright (c) 2019 Jinghui Zhai et al. This is an open access article distributed under the Creative Commons Attribution License, which permits unrestricted use, distribution, and reproduction in any medium, provided the original work is properly cited.

\begin{abstract}
High glucose and high fat are important inducements for the development and progression of diabetic cardiopathy. Salvianolic acid $\mathrm{B}$ (SAB), which is the most abundant and bioactive compound in Danshen, attenuates oxidative stress-related disorders, such as cardiovascular diseases, cerebral ischemia, and diabetes. However, the effect of SAB on diabetic cardiopathy is not clear. The aim of study was to investigate the effect and the underlying molecular mechanisms of SAB on diabetic cardiopathy in vitro model. The human umbilical vein endothelial (HUVEC) cells were treated with high glucose (HG, $30 \mathrm{mM}$ ) or high fat (palmitic acid, PA, 0.75 $\mathrm{mM})$ in the presence or absence of SAB $(100,200$, and $400 \mathrm{mg} / \mathrm{L})$ and incubated for $24 \mathrm{~h}$. We found that HG or PA induced apoptosis of HUVEC cells, while treatment with SAB inhibited the apoptosis. We also found that SAB reversed HG- or PA-induced oxidative stress, apoptosis cell cytokines production, and expression of thioredoxin-interacting protein (TXNIP). Moreover, SAB increased HG- or PA-induced expression of Sirtuin 1 (Sirt1), a nicotinamide adenine dinucleotide- $\left(\mathrm{NAD}^{+}\right.$-) dependent histone deacetylase. Exposure of HUVEC cells to Ex527 (Sirtl inhibitor) suppressed the effect of SAB on acetyl-p53 and procaspase-3 expressions. In conclusion, the results suggested that SAB could attenuate HUVEC cells damage treated with HG or PA via Sirtl and might be a potential therapy agent for the diabetic cardiopathy treatment.
\end{abstract}

\section{Introduction}

Diabetes mellitus (DM) is a metabolic disease with high worldwide incidence (4-5\%). DM patients compared with nondiabetic people bear up to sixfold higher risk of cardiovascular disease [1]. Endothelial dysfunction induced by glucotoxicity and lipotoxicity, which is a common problem in DM, has an important role in cardiovascular diseases [2]. Endothelial dysfunction results in increased oxidative stress and elevated levels of inflammatory markers due to increased oxygen free radical generation, lipid peroxides formation, impaired glutathione metabolism, and impaired antioxidant defense systems $[3,4]$. Thus, endothelial dysfunction is the early feature of cardiovascular complications in DM.

The dried root of Salvia miltiorrhiza Bunge (also known as Danshen) is popular in traditional Chinese medicine and has been used extensively to treat various diseases, including cerebrovascular diseases, coronary artery diseases, and myocardial infarction [5-8]. Salvianolic acid B (SAB; molecular formula: C36H30O16; Figure 1) is the most abundant and bioactive compound in Danshen and appears to have antioxidative and neuroprotective activities in vivo and in vitro [9-12]. Multiple studies have shown that SAB is used as a potent reactive oxygen species (ROS) scavenger and effectively attenuates oxidative stress-related disorders, such as cardiovascular diseases, cerebral ischemia, and diabetes [13-15]. It has been demonstrated that oxidative stress could accelerate the progress of diabetic cardiopathy. Excessive oxidative stress activates multiple intracellular signaling pathways and stimulates transcription factors, thus resulting in apoptosis [16]. Therefore, it is necessary to explore antioxidative agents for the diabetic cardiopathy treatment. Thioredoxin-interacting protein (TXNIP) has an important role in cellular metabolism. Increasing researches suggested that relationship of TXNIP and DM is close [17, 18]. It is an initial stage highly induced by diabetes and hyperglycemia. Furthermore, an important function of TXNIP is to interact with thioredoxin (TRX) and reduce ROS $[19,20]$. 
<smiles>O=C(O)O[C@H](Cc1ccc(O)c(O)c1)C(=O)/C=C/c1ccc(O)c2c1[C@@H](C(=O)O[C@H](Cc1ccc(O)c(O)c1)C(=O)O)[C@H](c1ccc(O)c(O)c1)O2</smiles>

FIGURE 1: Chemical structure of salvianolic acid B (SAB). Molecular formula: C36H30O16. Molecular weight: 718.6138.

Previous studies confirmed that SAB protected human endothelial cells from oxidative stress-induced cellular damage [21]. SAB is a potent activator of Sirtl in a variety of disease models $[13,22,23]$. Sirtuin 1 (Sirt1), a nicotinamide adenine dinucleotide- (NAD+-) dependent histone deacetylase, is involved in the regulation of metabolism, cell survival, differentiation, and longevity and exerts beneficial effects on glucose-lipid homeostasis and insulin secretion in diabetic patients [24]. Thus, it has been suggested that Sirtl is a key regulator of vascular senescence and dysfunction. It has been reported that the activation of Sirtl protects against vascular dysfunction in mice with diabetes [25]. However, it is not clear whether $\mathrm{SAB}$ can protect human umbilical vein endothelial (HUVEC) cells from high glucose or high fat associated with activating Sirtl.

Therefore, we hypothesized that $\mathrm{SAB}$ might benefit HUVEC cells against high glucose or high fat via Sirtl activation. To address the hypotheses, this study was aimed to investigate the potential effects of $\mathrm{SAB}$ on high glucose or high fat-induced HUVEC dysfunction. Firstly, we verified that SAB promoted HUVEC cells proliferation by MTT assay and inhibited apoptosis by flow cytometry assay, mitochondrial membrane potential assay, and western blotting assay. Secondly, SAB protected HUVEC cells from oxidative stress though suppressing expression of TXNIP. Finally, we found that Sirtl had an important role in SAB attenuating apoptosis of HG- or PA-induced HUVECs cells by present or absent Ex527 (Sirtl inhibitor).

\section{Materials and Methods}

2.1. Cell Culture. HUVECs were incubated in endothelial cell medium (ECM, Sciencell) containing endothelial cell growth supplement (ECGS), $10 \%$ fetal bovine serum (Sciencell), 100 $\mathrm{U} / \mathrm{L}$ penicillin, and $100 \mathrm{mg} / \mathrm{ml}$ streptomycin (Sciencell) and incubated at $37^{\circ} \mathrm{C}$ in $5 \% \mathrm{CO}_{2}$. Cell cultures were split once every 2 days.

\subsection{Cell Proliferation Detection Assay. HUVECs were seeded} in 96 -well plate with the density of $5 \times 10^{4}$ cell/well. Cells were treated with normal glucose $(5.5 \mathrm{mM}$ glucose $)$ or 10 $\mathrm{mM}$ glucose and $20 \mathrm{mM}$ glucose or high glucose $(30 \mathrm{mM}$ glucose $)$ in the presence or absence of SAB $(100 \mathrm{mg} / \mathrm{L}, 200$ $\mathrm{mg} / \mathrm{L}$, or $400 \mathrm{mg} / \mathrm{L})(\geq 98 \%$, Zhongshanlianjiu Biotechnology, Zhongshan, China). The other cells were treated with palmitic acid (PA, Sigma) $(0.25,0.5$, and $0.75 \mathrm{mM})$ or $0.75 \mathrm{mM}$ PA in the presence or absence of SAB $(100 \mathrm{mg} / \mathrm{L}, 200 \mathrm{mg} / \mathrm{L}$, or 400 $\mathrm{mg} / \mathrm{L})$. After $4 \mathrm{~h}, 12 \mathrm{~h}$, or $24 \mathrm{~h}, 10 \mu \mathrm{L}$ of $5 \mathrm{mg} / \mathrm{mL}$ MTT (3-[4, 5-dimethylthiazol- 2-yl]-2, 5-diphenyltetrazolium bromide, Sigma) solution was added per well and incubated for $4 \mathrm{~h}$. Subsequently, the supernatant was removed and $150 \mu \mathrm{L}$ DMSO was added to dissolve the formed formazan. The absorbance value was detected at $490 \mathrm{~nm}$ using a microplate spectrophotometer (ELX800).

2.3. Flow Cytometric Analysis of Cell Apoptosis. HUVECs were plated in 6-well plate overnight and treated with high glucose or PA in the presence or absence of SAB for $24 \mathrm{~h}$. At the end of treatment, the cells were collected and stained with Annexin V-FITC/PI apoptosis detection kit (Beyotime Biotechnology) according to manufacturer's instructions [26].

\subsection{Mitochondrial Membrane Potential Assay. HUVECs} were plated in 6-well plate overnight and treated with high glucose or PA in the presence or absence of SAB for $24 \mathrm{~h}$. JC-1 easily penetrates cells and healthy mitochondria. Briefly, after treatment, the cells were incubated at $37^{\circ} \mathrm{C}$ for $1 \mathrm{~h}$ with $5 \mathrm{mg} / \mathrm{L}$ JC-1 (Beyotime Biotechnology), then washed twice with PBS, and placed in fresh medium without serum. Lastly, images were captured with a fluorescence microscope (Olympus BX83, Olympus, Japan). The ratios of red/green fluorescent densities were calculated.

2.5. Detection of Oxidative Stress. The reactive oxygen species (ROS) level was evaluated using a Reactive Oxygen Species Assay Kit of DCFH-DA (Jiangcheng Bioengineering Institute, Nanjing, China) according to the manufacturer's instruction. The fluorescence intensity was analyzed with a microplate reader (Tecan, Switzerland) at an excitation wavelength of $488 \mathrm{~nm}$ and at an emission wavelength of $525 \mathrm{~nm}$.

2.6. Western Blotting. HUVECs were seeded into Petri dishes $(50 \mathrm{~mm} \times 50 \mathrm{~mm})$ and treated with high glucose $(30 \mathrm{mM})$ or PA $(0.75 \mathrm{mM})$ in the presence or absence of SAB (100 $\mathrm{mg} / \mathrm{L}, 200 \mathrm{mg} / \mathrm{L}$, or $400 \mathrm{mg} / \mathrm{L}$ ) for $24 \mathrm{~h}$. Then, the cells were extracted using lysis buffer ( $1 \mathrm{mM}$ PMSF, $50 \mathrm{mM}$ Tris, $1 \%$ SDS, sodium pyrophosphate, $\beta$-glycerophosphate, sodium orthovanadate, sodium fluoride, EDTA, leupeptin, and other inhibitors) (Beyotime Biotechnology, Shanghai, China). The protein concentration was detected using BCA assay kit (Beyotime Biotechnology). The lysates were then denatured at $100^{\circ} \mathrm{C}$ for $5 \mathrm{~min} .20 \mu \mathrm{g}$ proteins of each group were separated on SDS-PAGE, and then transferred onto PVDF membranes (Bio-Rad, CA). Membranes were blocked with 5\% nonfat milk for $1 \mathrm{~h}$ at room temperature and probed with primary antibodies against Bcl-2 (1:2000, Cell Signaling Technology), caspase-3 (1:2000, Cell Signaling Technology), caspase-9 (1:2000, Cell Signaling Technology), TXNIP (1:2000, Santa Cruz Biotechnology, Inc.), acetyl-p53 (1:2000, Abcam) and Sirt1 (1:2000, Abcam), and GAPDH (1:5000, Hangzhou Goodhere Biotechnology Co., Ltd.) at $4^{\circ} \mathrm{C}$ overnight. Then the membranes were washed with TBST and incubated with HRP-conjugated secondary antibodies (1:5000, Beyotime Biotechnology) for $1 \mathrm{~h}$ at room temperature. Finally, the 

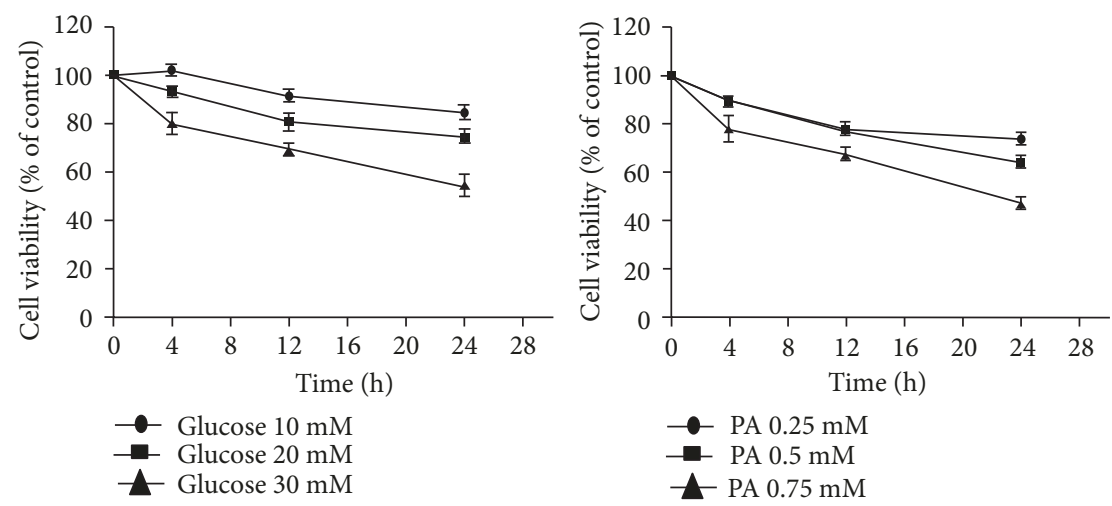

(a)
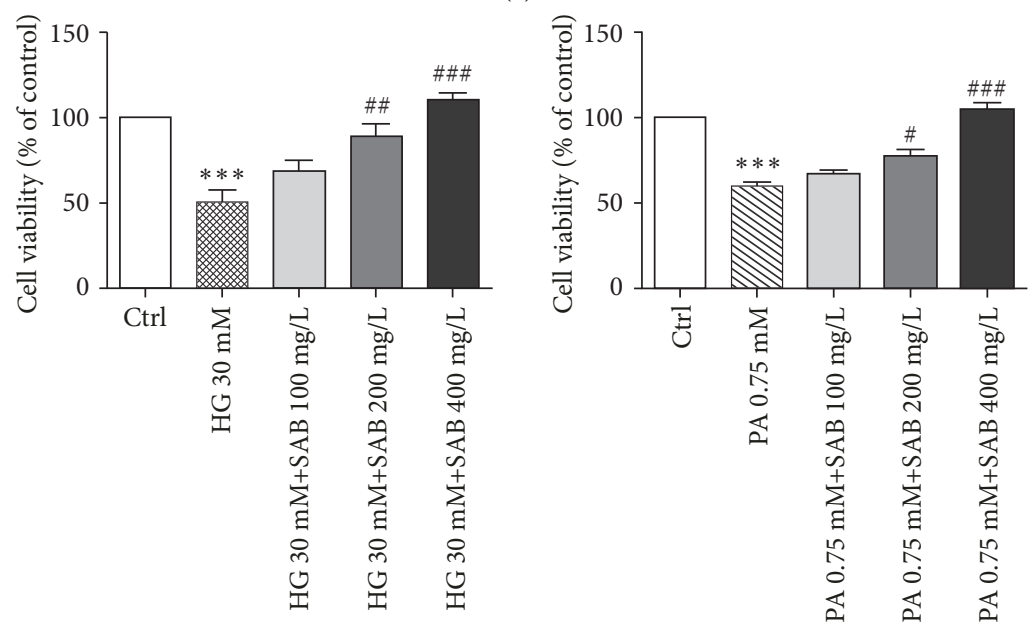

(b)
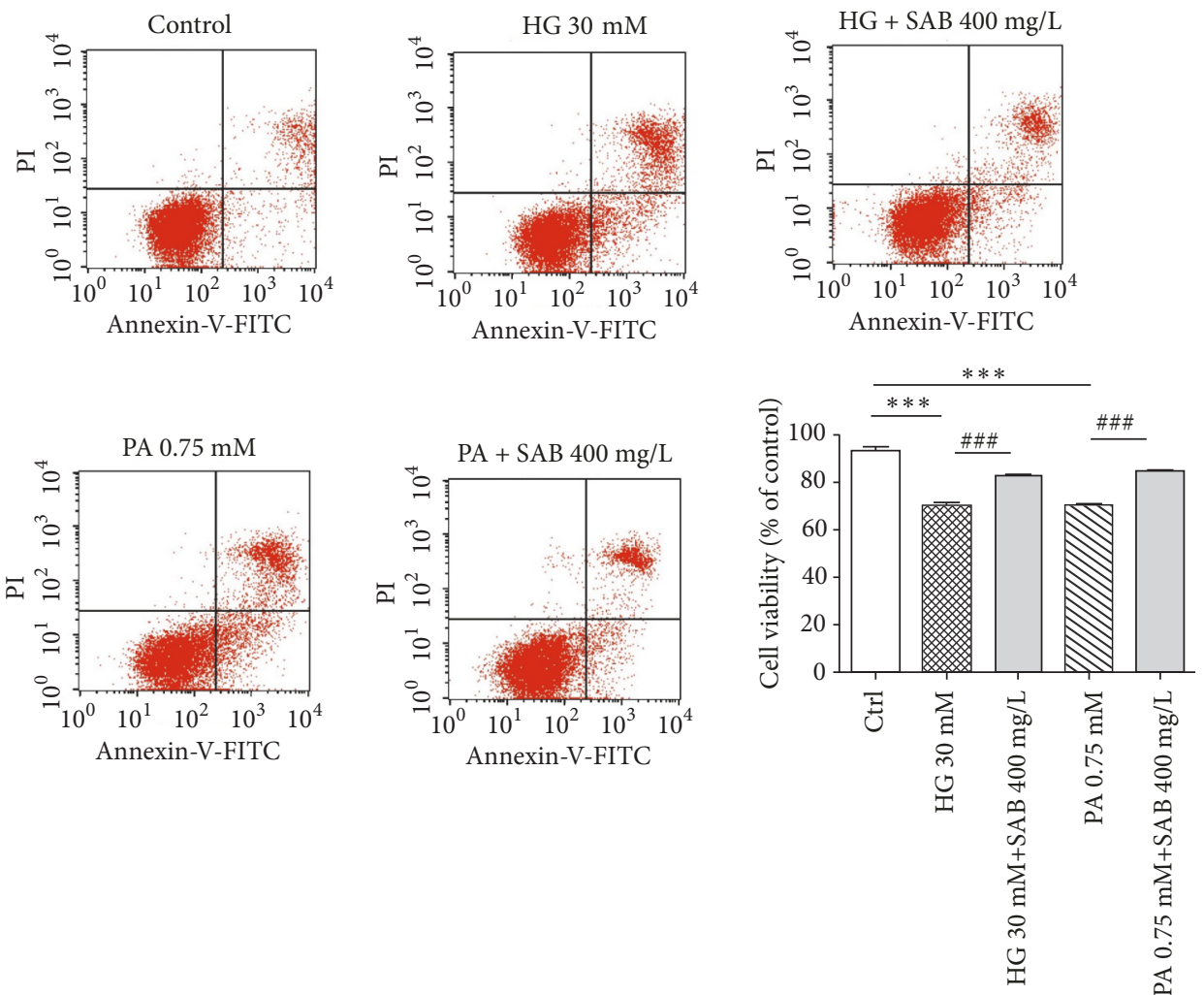

(c) (color)

Figure 2: Continued. 

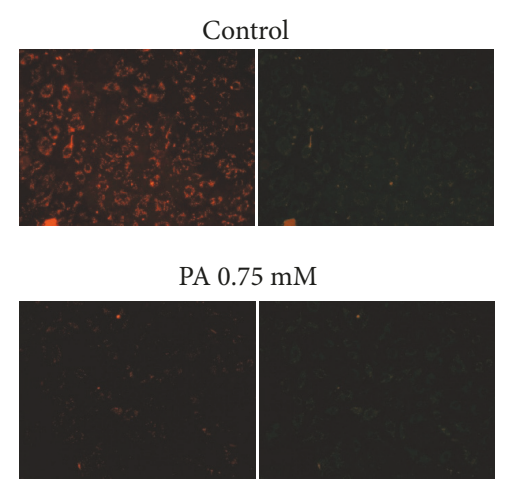
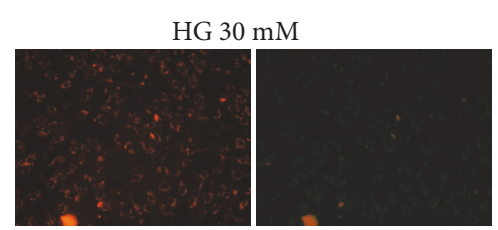

PA $0.75 \mathrm{mM}+\mathrm{SAB} 400 \mathrm{mg} / \mathrm{L}$

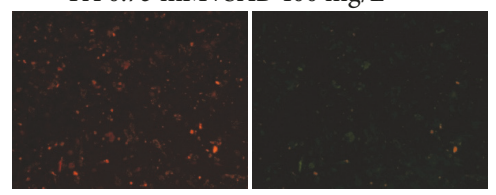

$* * *$

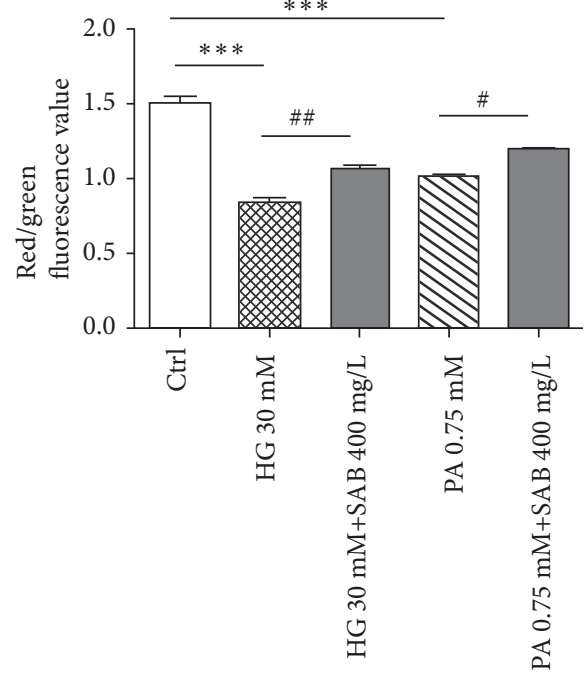

(d) (color)

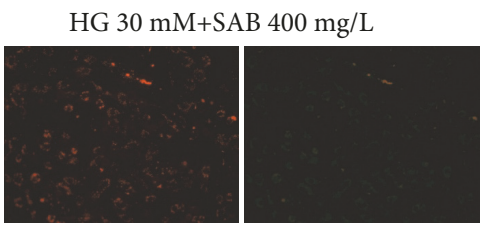

FIGURE 2: SAB reverses the inhibitory effects of high glucose or high fat (PA) on HUVEC cells proliferation and apoptosis. (a) Effect of glucose $(10,20$, and $30 \mathrm{mM})$ and PA $(0.25,0.5$, and $0.75 \mathrm{mM})$ on the percentage of survival in HUVECs at 4, 12, and 24 hours by MTT assay; (b) effect of HG $(30 \mathrm{mM})$ or PA $(0.75 \mathrm{mM})$ with SAB $(100,200$, and $400 \mathrm{mg} / \mathrm{L})$ on cells viabilities; $* * * p<0.001$ versus control group, ${ }^{\#} p<0.05$ versus HG or PA group, ${ }^{\# \#} p<0.01$ versus HG or PA group, and ${ }^{\# \#} p<0.001$ versus HG or PA group. (c) Effect of SAB on apoptosis induced by HG or PA in HUVECs after Annexin V and PI double staining; $* * * p<0.001$; ${ }^{\# \# \# ~} p<0.001$. (d) JC-1 staining assay for mitochondria membrane potential. SAB remained mitochondria membrane potential in HG- or PA-induced HUVEC cells; $* * * p<0.001 ;{ }^{\#} p<0.05,{ }^{\# \#} p<0.01$.

blots were imaged with ECL (Amersham, UK) and visualized on X-ray film (Kodak, China). The scanned digital images were quantified using ImageJ $1.37 \mathrm{c}$ software. All bands were normalized to GAPDH levels.

2.7. Immunofluorescence. Indirect immunofluorescence staining was used to observe the expression and localization of proteins, including Sirtl (1:200) and TXNIP (1:200), in HUVECs. HUVECs were plated in 12-well plate overnight, and treated with SAB in combination with high glucose or PA for $24 \mathrm{~h}$. After washing 3 times with cold PBS, HUVECs were fixed in $4 \%$ paraformaldehyde for 10 minutes at room temperature and then washed 3 times with PBS. After treatment with Triton X-100 and blocking with 5\% BSA, HUVECs were then incubated with primary antibodies overnight at $4^{\circ} \mathrm{C}$. After washing with PBS, HUVECs were incubated with corresponding FITC coupled secondary antibodies (Absin, Shanghai, China) for $1 \mathrm{~h}$ and counterstained with DAPI (Beyotime Biotechnology) for $10 \mathrm{~min}$.
Images were captured with a fluorescence microscope (Olympus BX83, Olympus, Japan).

2.8. Statistical Analysis. GraphPad Prism 5 software was used for all statistical analysis. Data are expressed as means \pm standard error of the mean (SEM) of three or more independent experiments. The unpaired Student's t-test or one-way ANOVA followed by Tukey test was used for pairwise comparisons among groups where appropriate, with significance established as $\mathrm{p}<0.05$.

\section{Results}

3.1. SAB Inhibited HG- or PA-Induced Proliferation and Apoptosis of HUVEC Cells. HUVEC cells were cultured under the conditions of glucose $(10,20$, and $30 \mathrm{mM})$ or palmitic acid (PA, 0.25, 0.5, and $0.75 \mathrm{mM}$ ) for $4 \mathrm{~h}, 12 \mathrm{~h}$, and 24 h. Cells proliferation was evaluated using the MTT assay. The results in Figure 2(a) suggested that both high glucose 


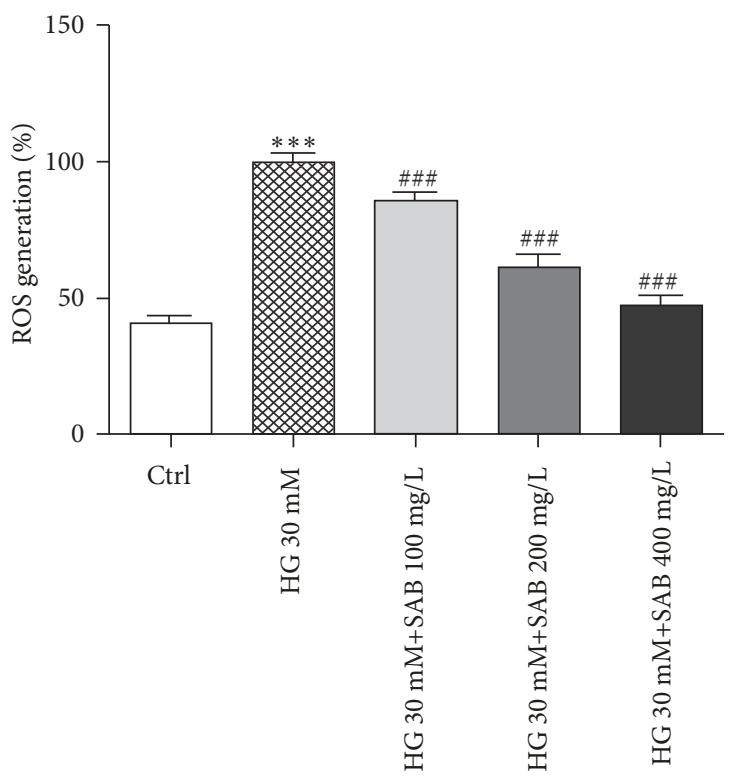

(a)

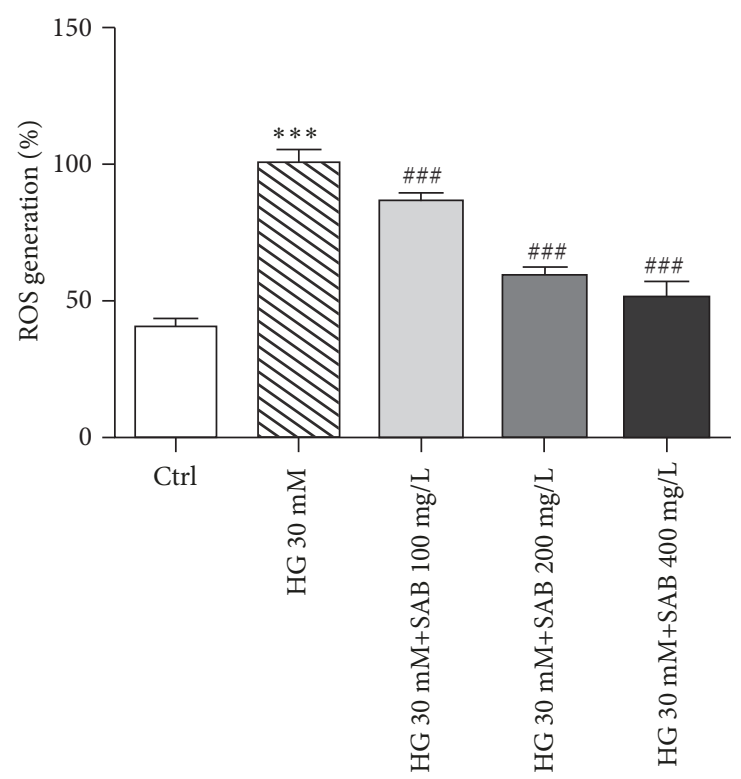

(b)

FIGURE 3: SAB reverses the effects of HG or PA on HUVEC cells ROS production. (a) Effect of SAB (100, 200, and 400 mg/L) with HG on ROS generation in HUVEC cells. (b) Effect of SAB $(100,200$, and $400 \mathrm{mg} / \mathrm{L}$ ) with PA on ROS generation in HUVEC cells. $* * * p<0.001$ versus control group, ${ }^{\#} p<0.05$ versus HG or PA group, and ${ }^{\# \#} p<0.001$ versus HG or PA group.

and high fat-induced cell viability decrease by concentration gradient and time gradient. The doses of $30 \mathrm{mM}$ glucose and $0.75 \mathrm{mM}$ PA treated for $24 \mathrm{~h}$ were used for further experiments. We found a dose dependent increase in cell viability upregulating exposure to coadministration of SAB $(100,200$, and $400 \mathrm{mg} / \mathrm{L}$ ) and HG or PA (Figure 2(b)). From Figure 2(c), HUVEC cells apoptosis induced by HG or PA were prevented by SAB significant $(\mathrm{P}<0.001)$.

Mitochondria, as the primary site of cellular energy generation and oxygen consumption, represent a likely pathway for HG- or PA-induced apoptosis [27]. In this study, we observed that SAB significantly prevented impaired mitochondrial bioenergetics by retaining mitochondria membrane potential (Figure 2(d)).

3.2. SAB Reverses the Effects of HG or PA on HUVEC Cells ROS Production. As oxidative stress is crucial for the HG- or PA-induced cell injury, level of ROS were assessed. As shown in Figure 3, compared to the control group, intracellular ROS levels in HUVEC cells were markedly elevated in response to HG or PA treatment, and the increase was inhibited by treatment with $\mathrm{SAB}$.

3.3. SAB Reduces Apoptosis Related Proteins and Involves Bcl2, Procaspase-3, and Procaspase-9 Activation. To determine whether the protective effects of $\mathrm{SAB}$ are associated with apoptosis, we measured the levels of $\mathrm{Bcl}-2$, procaspase- 3 and procaspase- 9 expressions. HG or PA conditions decreased expression of $\mathrm{Bcl}-2$, procaspase-3, and procaspase-9. However, all these effects were reversed dose-dependently by SAB (Figures 4(a) and 4(b)). These results indicate that SAB inhibits apoptosis induced by HG or PA associated with Bcl-2, caspase-3, and caspase- 9 proteins.

3.4. SAB Modulates the Expression of TXNIP and Sirt1. To explore the related mechanism of the SAB effect in HG- or PA-induced HUVEC cells, the expression levels of TXNIP and Sirtl were detected by western blotting. TXNIP, which is the thioredoxin binding protein, acts as a mediator of cellular metabolism. It was found that TXNIP mediates glucoseinduced apoptotic death in pancreatic beta cells [28, 29]. As shown in Figure 5, we found that HG or PA conditions reduced the expression levels of Sirt1 $(p<0.001 ; p<0.005)$, an effect that was reversed by SAB treatment $(p<0.001 ; p<$ 0.01). Additionally, compared to the control group, TXNIP expression was significantly increased in response to $\mathrm{HG}$ or PA stimulation $(p<0.001)$ but was decreased in SABtreated cells $(p<0.001 ; p<0.005)$. Fluorescence intensities of Sirtl and TXNIP coincided with results of western blotting (Figure 6).

3.5. Inhibition of Sirt1 Expression Reversed the Effect of $H G$ or $P A$ and $S A B$ on HUVEC Cells. To evaluate the relation among Sirtl in the effect of SAB in $\mathrm{HG}^{-}$or PA-induced HUVEC cells, the HUVEC cells were incubated with the Ex527 (inhibitor of Sirt1) to pharmacologically inhibit the expression of Sirt1. As shown in Figure 7, SAB significantly suppressed the expression of A-p53 compared to the high glucose group, whereas Ex527 reversed the effects of SAB. At the same time, we measured the effects of Ex527 on expression of procaspase- 3 and further confirmed that Sirtl acts on SAB to alleviate the cellular apoptosis induced by HG or PA. 

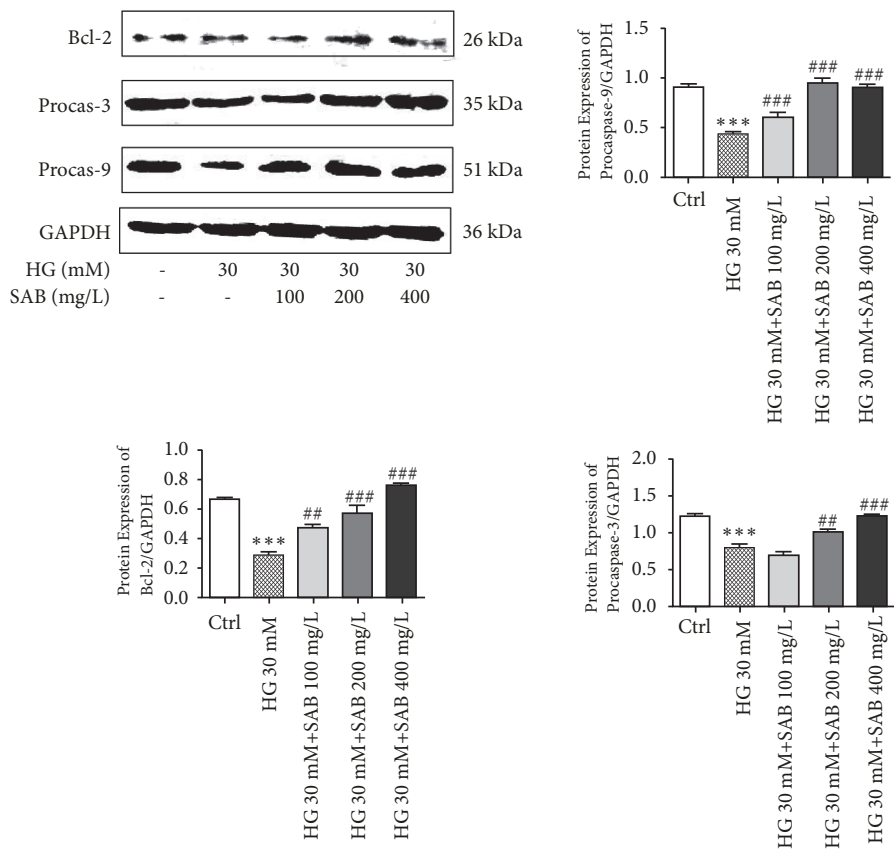

(a)
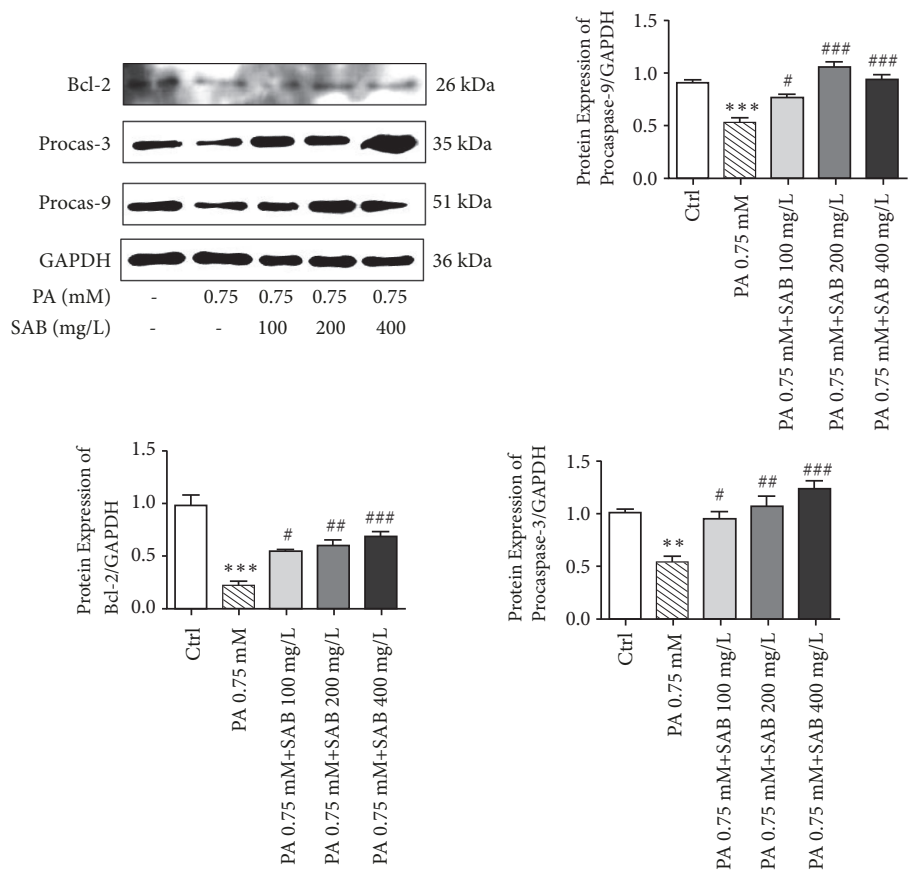

(b)

Figure 4: SAB increased expressions of procaspase-3, procaspase- 9 , and Bcl-2 in response to HG (a) or PA (b) conditions. $* * * p<0.001$ versus control group, ${ }^{\#} p<0.05$ versus high glucose group, ${ }^{\# \#} p<0.01$ versus high glucose group, and ${ }^{\# \#} p<0.001$ versus high glucose group.

\section{Discussion}

The main purpose of this study was to direct attention to the relationship between Sirtl and the potential effects of SAB on HUVEC cells treated by high glucose or high fat. We demonstrated that SAB could attenuate endothelial dysfunction by dramatically upregulating expression of Sirtl.
Moreover, we found that the inhibitor of Sirtl abolished protective function of SAB. Our research provided a potential novel approach and mechanism for the treatment of diabetic cardiopathy.

It is well known that endothelial dysfunction is a matter marker of numerous cardiovascular diseases. In an in vitro study, HUVEC cells were cultured under high glucose or 

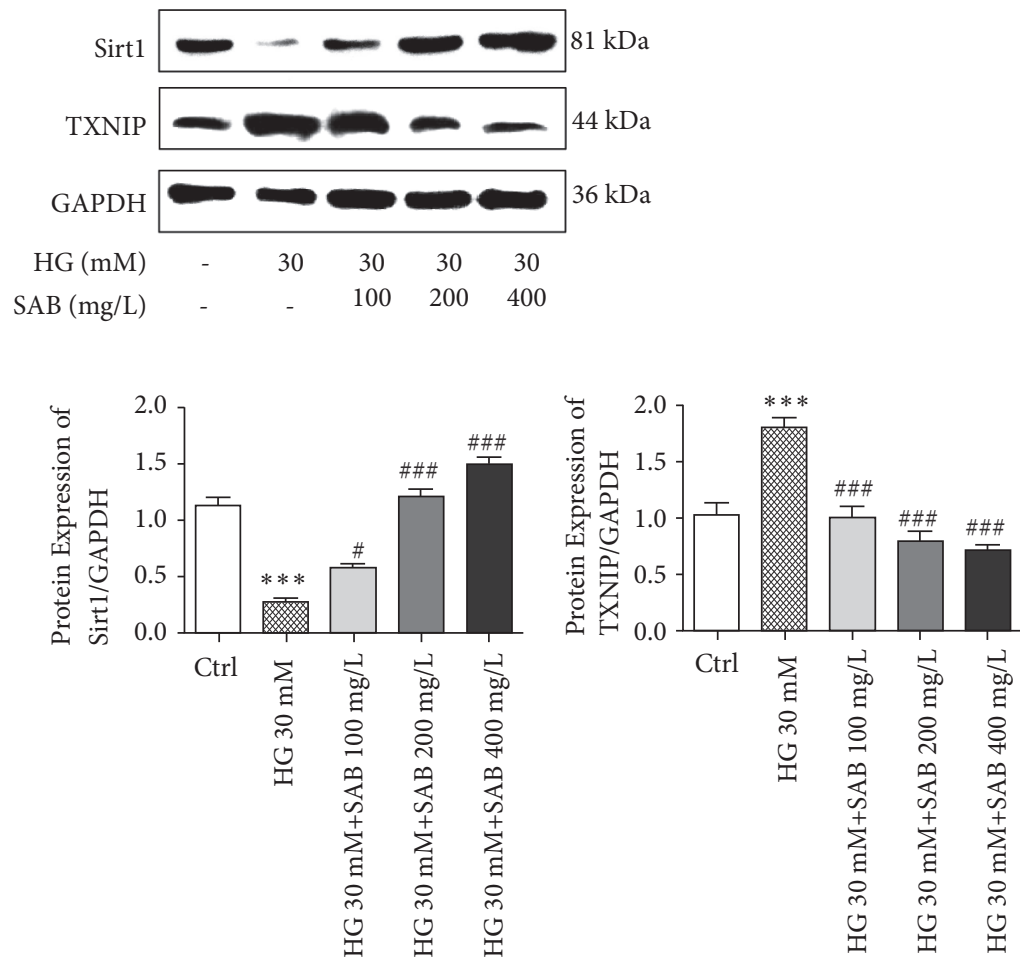

(a)
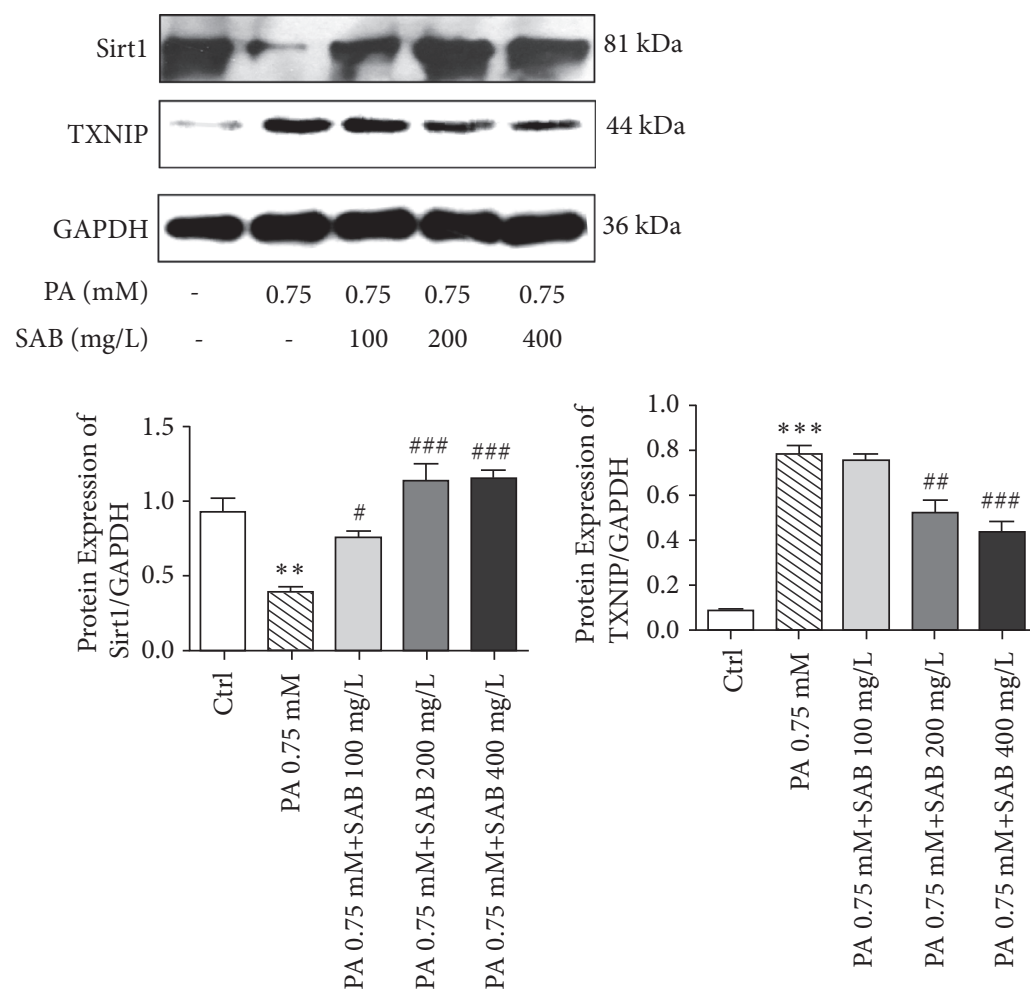

(b)

FIGURE 5: SAB modulates the expression of Sirtl and TXNIP in HUVEC cells treated by HG (a) or PA (b). $* * * p<0.001$ versus control group, $* * p<0.01$ versus control group, ${ }^{\#} p<0.05$ versus HG or PA group, ${ }^{\#} p<0.01$ versus HG or PA group, and ${ }^{\# \# \#} p<0.001$ versus HG or PA group. 


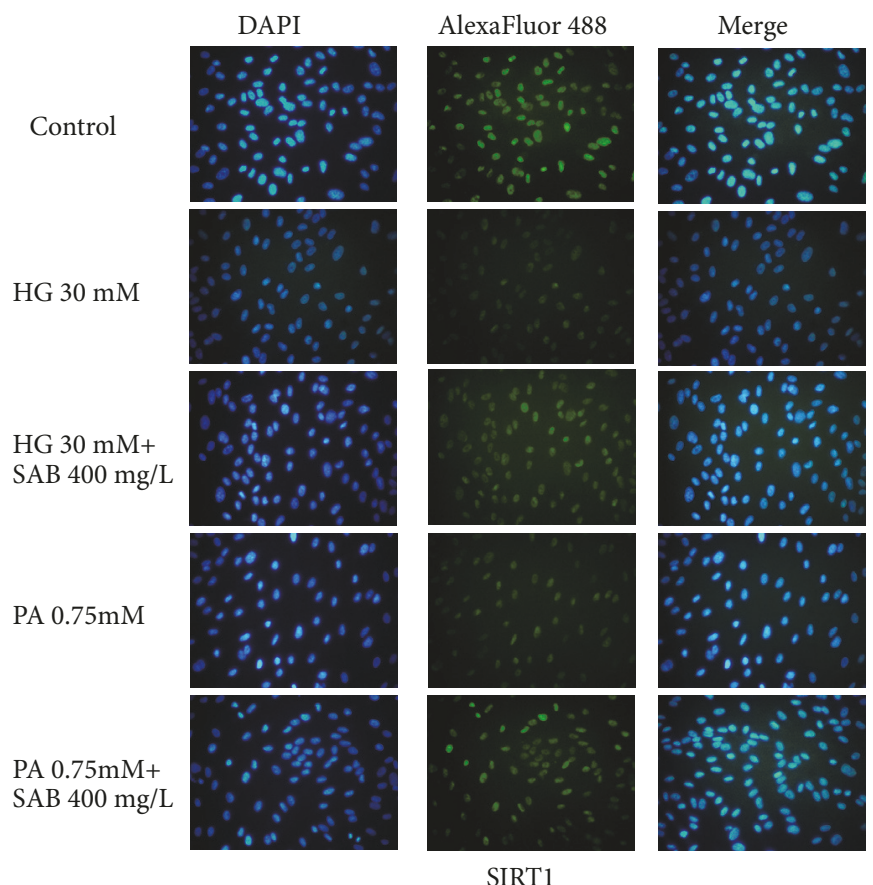

(a) (color)

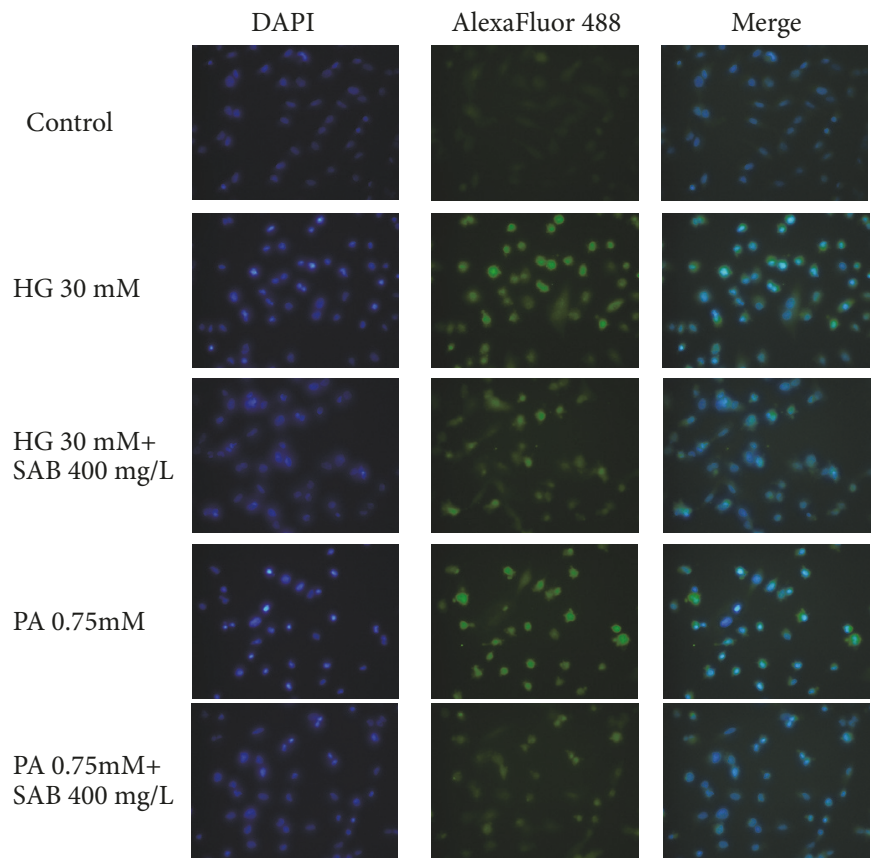

TXNIP

(b) (color)

FIGURE 6: Effect of SAB (400 mg/L) on fluorescence intensity of Sirtl (a) and TXNIP (b) in HG- or PA-induced HUVEC cells.

high fat conditions to establish a cell model of cardiovascular disease of DM. In previous our study, we demonstrated that salvianolic acid ( $\mathrm{Sa}$ ) could inhibit the vascular endothelial dysfunction induced by high glucose [26]. SAB is one component of Sa; therefore we investigated effect of SAB on diabetic cardiopathy, though high glucose or high fat model to prove that $\mathrm{SAB}$ is a major effective component of Sa.
Decreased HUVEC cells proliferation is a major pathological feature in the early stage of cardiovascular disease of DM. The Bcl-2 protein family and caspase family play a key role in the regulation of cell apoptosis [30]. Overexpression of Bcl-2 can inhibit cell apoptosis, and caspases activate the upstream of apoptosis [31]. Moreover, the Bcl-2 control the permeability of mitochondria and the release of cytochrome 

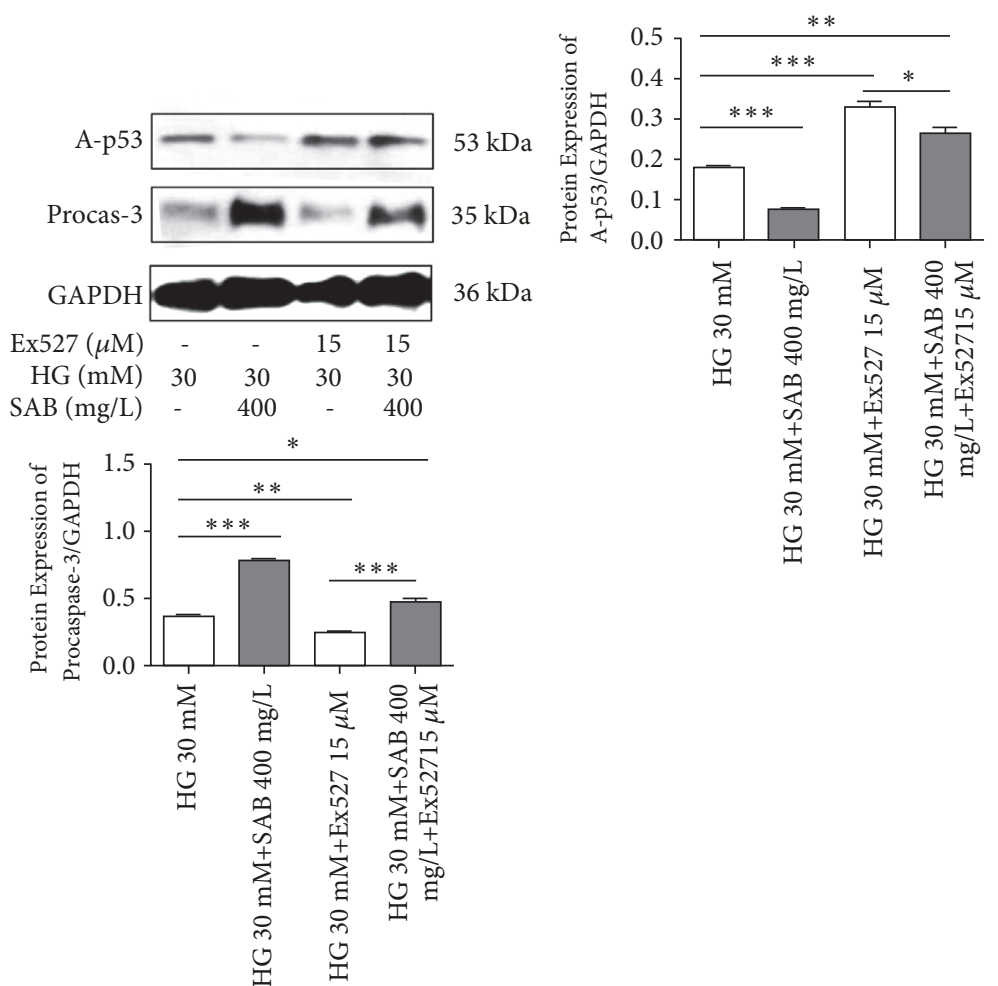

(a)
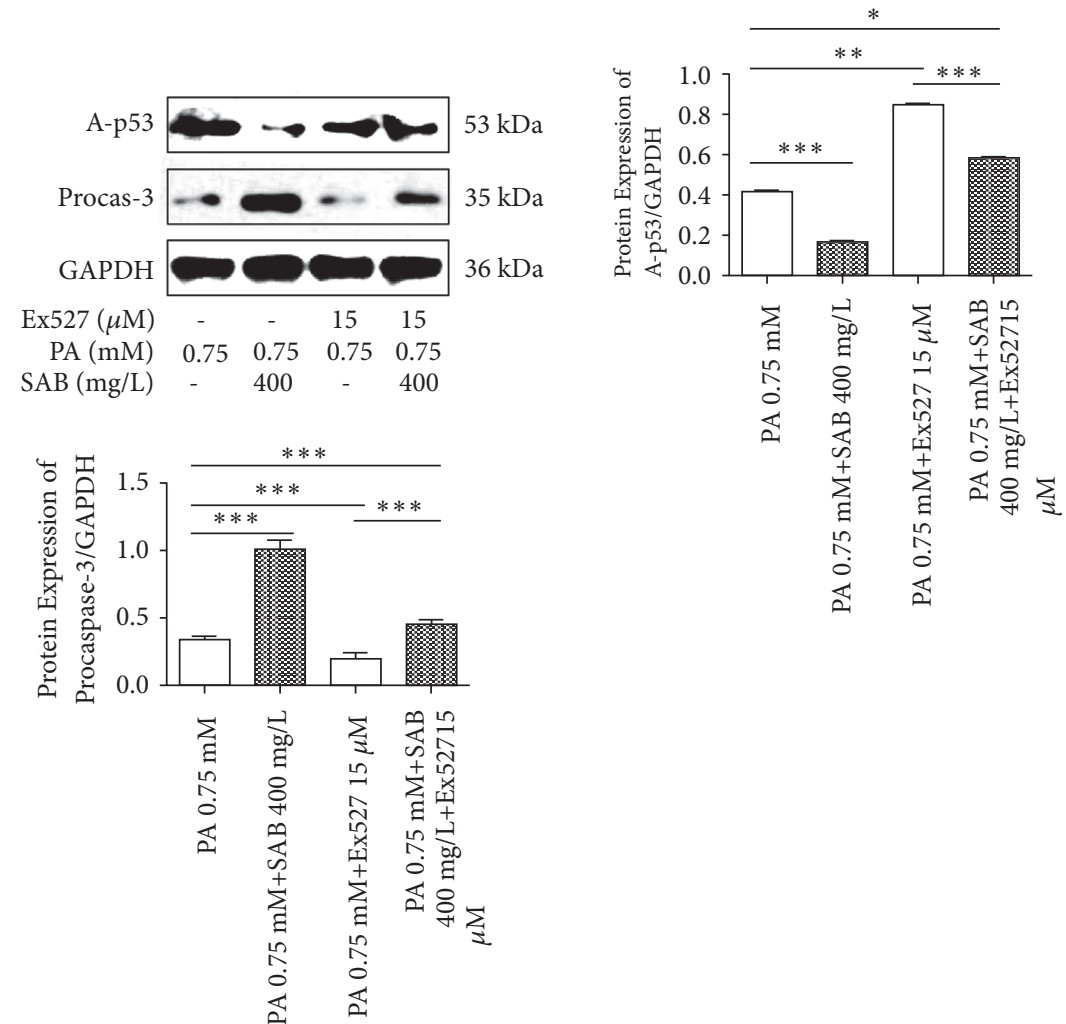

(b)

FIGURE 7: Effect of SAB was reversed on expressions of acetyl-p53 and procaspase- 3 by Ex527 (15 $\mu \mathrm{M})$ in HG (a)- or PA (b)-induced HUVEC cells. $* p<0.05$ versus control group, $* * p<0.01$ versus control group, $* * * p<0.001$ versus control group, ${ }^{*} p<0.05$ versus Ex527 group, and $\# p<0.01$ versus Ex527 group. 
c to the cytoplasm, following the activation of a group of caspases, which proceeds apoptosis. Among caspases family, caspase- 9 and caspase-3 are the most representative [32]. Caspase-3 can activate intrinsic apoptosis, while caspase9 can increase ROS accumulation. Our data also revealed the potent effect of $\mathrm{SAB}$ reversed cell apoptosis induced by high glucose or PA relative to Bcl-2 and caspase families.

As is well known, apoptosis is closely related to oxidative stress. SAB is a new generation of the natural antioxidants, which has a plurality of phenolic hydroxyl group, so it has strong antioxidant activity. It has been reported that $\mathrm{SAB}$ inhibits HG-induced oxidative stress and reduces the generation of ROS and mitochondrial depolarization [33]. It well know that ROS of the patients with hyperglycemia or hyperlipidemia is from many different aspects, including protein glycation, PKC activation, the mitochondrial oxidative phosphorylation, and $\mathrm{NAD}(\mathrm{P}) \mathrm{H}$ oxidase activation [34, 35]. Hence, inhibition of ROS overproduction can relief patients with hyperglycemia or depolarization contributed to reduce cellular oxidative stress and promote cells recovery. Thioredoxin-interacting protein (TXNIP), which is an early response gene highly induced by diabetes and hyperglycemia, acts as a mediator of cellular metabolism [36]. TXNIP was initially identified as one of the proteins that interacts with thioredoxin (TRX) and reduces its function which scavenges ROS [37]. It was found that TXNIP mediates glucose-induced apoptotic death in pancreatic beta cells [38]. In our study, we found that SAB could clean away over ROS very well and decreased the expression of TXNIP induced by high glucose or PA.

Sirtl is a crucial regulator of vascular dysfunction and exerts beneficial effect on glucose-lipid homeostasis in DM. Intriguingly, the inhibition of Sirtl with pharmacological agent leads to an elevation of ROS levels, indicating a definite relationship between Sirtl and ROS [39]. The previous experiment proved that Lithospermic acid B can significantly reduce death of beta cells and promote activity of Sirtl [40]. While SAB also mediates redox state, we deduced that SAB may have a potent ability to upregulate Sirtl expression. In our experiment, western blot assay showed that expression of Sirtl was increased by SAB in HUVECs treated with high glucose or PA.

Based on the information stated above, exploring the effect of SAB on Sirtl expression in HUVEC cells is crucial. To clarify it, we measured expression of Sirt1 in HUVEC cells inhibited by Ex527 or not. The data suggested that inhibition of Sirtl attenuated SAB function in HUVEC cells treated with high glucose or PA.

\section{Conclusion}

To conclude, the effects of SAB on two HUVEC cells models were investigated in the present study. The results demonstrated that $\mathrm{SAB}$ attenuated the $\mathrm{HG}$ - or PA-induced cell apoptosis in HUVEC cells via increasing Bcl-2, procaspase3 , and procaspase-9, suppressing TXNIP and activating Sirtl expressions. The data suggested that SAB might be a promising agent for the therapy of cardiovascular disease of
DM. However, the study is a preliminary in vitro study, and further in vivo experiments are needed.

\section{Data Availability}

The data used to support the findings of this study are included within the article.

\section{Conflicts of Interest}

The authors declare that they have no conflicts of interest.

\section{Acknowledgments}

This work was supported by the National Natural Science Foundation of China (Grants nos. 81503168 and 818803608).

\section{References}

[1] A. Juutilainen, S. Lehto, T. Rönnemaa, K. Pyörälä, and M. Laakso, "Type 2 diabetes as a "coronary heart disease equivalent": An 18-year prospective population-based study in Finnish subjects," Diabetes Care, vol. 28, no. 12, pp. 2901-2907, 2005.

[2] K. Feidantsis, K. Mellidis, E. Galatou, Z. Sinakos, and A. Lazou, "Treatment with crocin improves cardiac dysfunction by normalizing autophagy and inhibiting apoptosis in STZ-induced diabetic cardiomyopathy," Nutrition, Metabolism \& Cardiovascular Diseases, vol. 28, no. 9, pp. 952-961, 2018.

[3] Z. Guo, Z. Xia, J. Jiang, and J. H. McNeill, "Downregulation of NADPH oxidase, antioxidant enzymes, and inflammatory markers in the heart of streptozotocin-induced diabetic rats by $\mathrm{N}$-acetyl-L-cysteine," American Journal of Physiology-Heart and Circulatory Physiology, vol. 292, no. 4, pp. H1728-H1736, 2007.

[4] N. Li, F. Frigerio, and P. Maechler, "The sensitivity of pancreatic $\beta$-cells to mitochondrial injuries triggered by lipotoxicity and oxidative stress," Biochemical Society Transactions, vol. 36, no. 5, pp. 930-934, 2008.

[5] M. Shi, F. Huang, C. Deng, Y. Wang, and G. Kai, “ Bioactivities, biosynthesis and biotechnological production of phenolic acids in Salvia miltiorrhiza," Critical Reviews in Food Science and Nutrition, pp. 1-12, 2018.

[6] L. Zhou, Z. Zuo, and M. S. S. Chow, "Danshen: an overview of its chemistry, pharmacology, pharmacokinetics, and clinical use," Clinical Pharmacology and Therapeutics, vol. 45, no. 12, pp. 1345-1359, 2005.

[7] Y.-B. Wu, Z.-Y. Ni, Q.-W. Shi et al., "Constituents from Salvia species and their biological activities," Chemical Reviews, vol. 112, no. 11, pp. 5967-6026, 2012.

[8] M. Kim, J. H. Bang, J. Lee et al., "Salvia miltiorrhiza extract protects white matter and the hippocampus from damage induced by chronic cerebral hypoperfusion in rats," $B M C$ Complementary and Alternative Medicine, vol. 15, no. 1, 2015.

[9] J. Zhang, X. Xie, M. Tang et al., "Salvianolic acid B promotes microglial M2-polarization and rescues neurogenesis in stressexposed mice," Brain, Behavior, and Immunity, vol. 66, pp. 111124, 2017.

[10] J.-Q. Zhang, X.-H. Wu, Y. Feng et al., "Salvianolic acid B ameliorates depressive-like behaviors in chronic mild stress-treated mice: Involvement of the neuroinflammatory pathway," Acta Pharmacologica Sinica, vol. 37, no. 9, pp. 1141-1153, 2016. 
[11] Y. Tang, A. Jacobi, C. Vater, X. Zou, and M. Stiehler, "Salvianolic acid B protects human endothelial progenitor cells against oxidative stress-mediated dysfunction by modulating Akt/mTOR/4EBP1, p38 MAPK/ATF2, and ERK1/2 signaling pathways," Biochemical Pharmacology, vol. 90, no. 1, pp. 34-49, 2014.

[12] X. Zhang, Q. Wu, Y. Lu et al., "Cerebroprotection by salvianolic acid B after experimental subarachnoid hemorrhage occurs via Nrf2- and SIRT1-dependent pathways," Free Radical Biology \& Medicine, vol. 124, pp. 504-516, 2018.

[13] H. Lv, L. Wang, J. Shen et al., "Salvianolic acid B attenuates apoptosis and inflammation via SIRT1 activation in experimental stroke rats," Brain Research Bulletin, vol. 115, pp. 30-36, 2015.

[14] Y. Deng, M. Yang, F. Xu et al., "Combined salvianolic acid B and ginsenoside Rgl exerts cardioprotection against ischemia/ reperfusion injury in rats," PLoS ONE, vol. 10, no. 8, Article ID e0135435, 2015.

[15] Y. Ren, S. Tao, S. Zheng et al., "Salvianolic acid B improves vascular endothelial function in diabetic rats with blood glucose fluctuations via suppression of endothelial cell apoptosis," European Journal of Pharmacology, vol. 791, pp. 308-315, 2016.

[16] A. Nafisa, S. G. Gray, Y. Cao et al., "Endothelial function and dysfunction: impact of metformin," Pharmacology \& Therapeutics, vol. 192, pp. 150-162, 2018.

[17] A. Szpigel, I. Hainault, A. Carlier et al., "Lipid environment induces ER stress, TXNIP expression and inflammation in immune cells of individuals with type 2 diabetes," Diabetologia, vol. 61, no. 2, pp. 399-412, 2018.

[18] C. Soriano-Tárraga, J. Jiménez-Conde, E. Giralt-Steinhauer et al., "Epigenome-wide association study identifies TXNIP gene associated with type 2 diabetes mellitus and sustained hyperglycemia," Human Molecular Genetics, vol. 25, no. 3, pp. 609619, 2016.

[19] Y. Han, X. Xu, C. Tang et al., "Reactive oxygen species promote tubular injury in diabetic nephropathy: The role of the mitochondrial ros-txnip-nlrp3 biological axis," Redox Biology, vol. 16, pp. 32-46, 2018.

[20] J. Li, Z. Yue, W. Xiong, P. Sun, K. You, and J. Wang, “TXNIP overexpression suppresses proliferation and induces apoptosis in SMMC7221 cells through ROS generation and MAPK pathway activation," Oncology Reports, vol. 37, no. 6, pp. 3369-3376, 2017.

[21] H. Kuang, Y. Wang, J. Hu, C. Wang, S. Lu, and X. Mo, "A Method for Preparation of an Internal Layer of Artificial Vascular Graft Co-Modified with Salvianolic Acid B and Heparin," ACS Applied Materials \& Interfaces, vol. 10, no. 23, pp. 19365-19372, 2018.

[22] W. Zeng, W. Shan, L. Gao et al., "Inhibition of HMGB1 release via salvianolic acid B-mediated SIRT1 up-regulation protects rats against non-alcoholic fatty liver disease," Scientific Reports, vol. 5, Article ID 16013, 2015.

[23] M. Li, Y. Lu, Y. Hu et al., "Salvianolic acid B protects against acute ethanol-induced liver injury through SIRT1-mediated deacetylation of p53 in rats," Toxicology Letters, vol. 228, no. 2, pp. 67-74, 2014.

[24] M. Kitada and D. Koya, "SIRT1 in type 2 diabetes: mechanisms and therapeutic potential," Diabetes \& Metabolism, vol. 37, no. 5, pp. 315-325, 2013.

[25] M. Kassan, A. Vikram, Q. Li et al., "MicroRNA-204 promotes vascular endoplasmic reticulum stress and endothelial dysfunction by targeting Sirtuinl," Scientific Reports, vol. 7, no. 1, 2017.
[26] J. Zhai, X. Qu, Y. Zhang et al., "Salvianolic acid inhibits the effects of high glucose on vascular endothelial dysfunction by modulating the Sirtl-eNOS pathway," Journal of Biochemical and Molecular Toxicology, vol. 33, no. 2, p. e22245, 2019.

[27] P. Liao, D. Yang, D. Liu, and Y. Zheng, "GLP-1 and ghrelin attenuate high glucose/high lipid-induced apoptosis and senescence of human microvascular endothelial cells," Cellular Physiology and Biochemistry, vol. 44, no. 5, pp. 1842-1855, 2018.

[28] W. Qi, X. Chen, R. E. Gilbert et al., "High glucose-induced thioredoxin-interacting protein in renal proximal tubule cells is independent of transforming growth factor- $\beta 1$," The American Journal of Pathology, vol. 171, no. 3, pp. 744-754, 2007.

[29] C. A. Stoltzman, C. W. Peterson, K. T. Breen, D. M. Muoio, A. N. Billin, and D. E. Ayer, "Glucose sensing by MondoA:Mlx complexes: A role for hexokinases and direct regulation of thioredoxin-interacting protein expression," Proceedings of the National Acadamy of Sciences of the United States of America, vol. 105, no. 19, pp. 6912-6917, 2008.

[30] W. A. Siddiqui, A. Ahad, and H. Ahsan, "The mystery of BCL2 family: Bcl-2 proteins and apoptosis: an update," Archives of Toxicology, vol. 89, no. 3, pp. 289-317, 2015.

[31] K. Shimada, T. R. Crother, J. Karlin et al., "Oxidized mitochondrial DNA activates the NLRP3 inflammasome during apoptosis," Immunity, vol. 36, no. 3, pp. 401-414, 2012.

[32] M. S. Aguzzi, C. Giampietri, F. De Marchis et al., "RGDS peptide induces caspase 8 and caspase 9 activation in human endothelial cells," Blood, vol. 103, no. 11, pp. 4180-4187, 2004.

[33] Z. Sun, Y. Ma, F. Chen, S. Wang, B. Chen, and J. Shi, "Artesunate ameliorates high glucose-induced rat glomerular mesangial cell injury by suppressing the TLR4/NF- $\kappa \mathrm{B} / \mathrm{NLRP} 3$ inflammasome pathway," Chemico-Biological Interactions, vol. 293, pp. 11-19, 2018.

[34] R. A. Kowluru, M. Mishra, A. Kowluru, and B. Kumar, "Hyperlipidemia and the development of diabetic retinopathy: Comparison between type 1 and type 2 animal models," Metabolism - Clinical and Experimental, vol. 65, no. 10, pp. 1570-1581, 2016.

[35] A. Padilla, M. Descorbeth, A. L. Almeyda, K. Payne, and M. De Leon, "Hyperglycemia magnifies Schwann cell dysfunction and cell death triggered by PA-induced lipotoxicity," Brain Research, vol. 1370, pp. 64-79, 2011.

[36] J. Chen, G. Saxena, I. N. Mungrue, A. J. Lusis, and A. Shalev, "Thioredoxin-interacting protein: a critical link between glucose toxicity and $\beta$-cell apoptosis," Diabetes, vol. 57, no. 4 , pp. 938-944, 2008.

[37] M. T. Forrester, D. Seth, A. Hausladen et al., “Thioredoxininteracting protein (Txnip) is a feedback regulator of Snitrosylation," The Journal of Biological Chemistry, vol. 284, no. 52, pp. 36160-36166, 2009.

[38] C. Y. Liu, Y. N. Hao, F. Yin, Y. L. Zhang, and J. H. Liu, "Geniposide accelerates proteasome degradation of Txnip to inhibit insulin secretion in pancreatic $\beta$-cells," Journal of Endocrinological Investigation, vol. 40, no. 5, pp. 505-512, 2017.

[39] W. Zhang, Q. Huang, Z. Zeng, J. Wu, Y. Zhang, and Z. Chen, "Sirtl inhibits oxidative stress in vascular endothelial cells," Oxidative Medicine and Cellular Longevity, vol. 2017, 2017.

[40] B.-W. Lee, S. W. Chun, S. H. Kim et al., "Lithospermic acid B protects beta-cells from cytokine-induced apoptosis by alleviating apoptotic pathways and activating anti-apoptotic pathways of Nrf2-HO-1 and Sirt1," Toxicology and Applied Pharmacology, vol. 252, no. 1, pp. 47-54, 2011. 


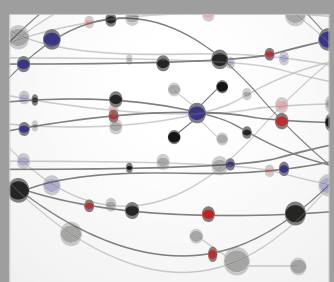

The Scientific World Journal
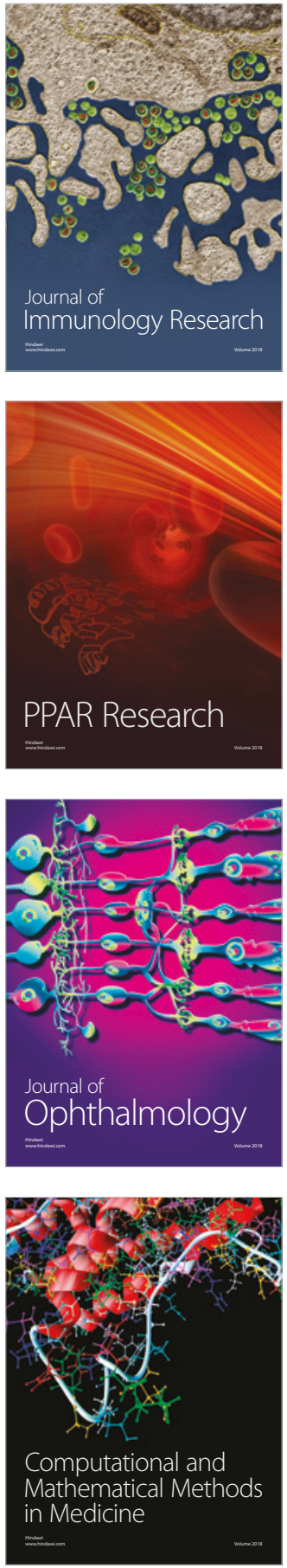

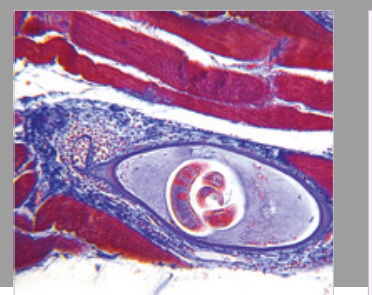

Gastroenterology Research and Practice

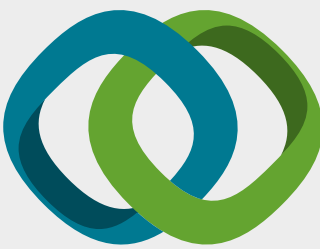

\section{Hindawi}

Submit your manuscripts at

www.hindawi.com
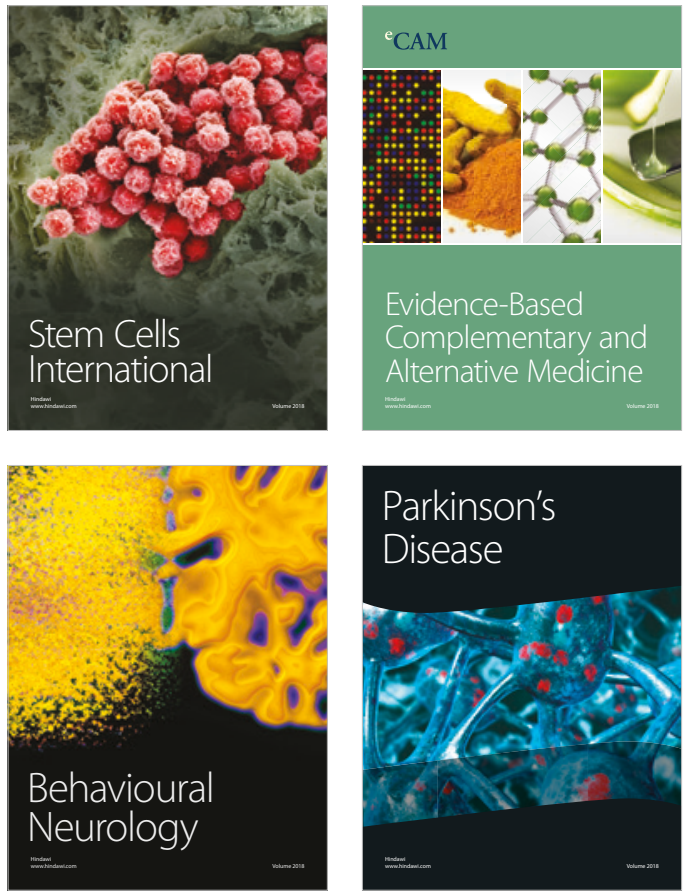

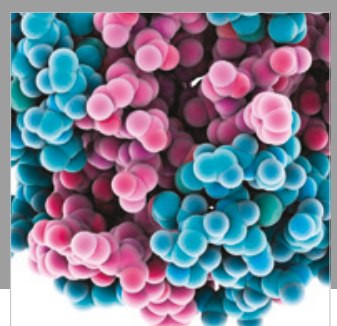

ournal of

Diabetes Research

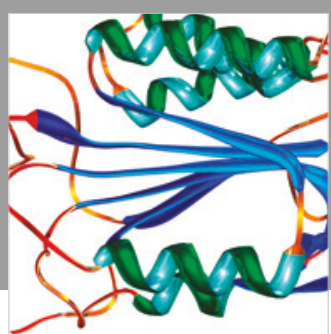

Disease Markers
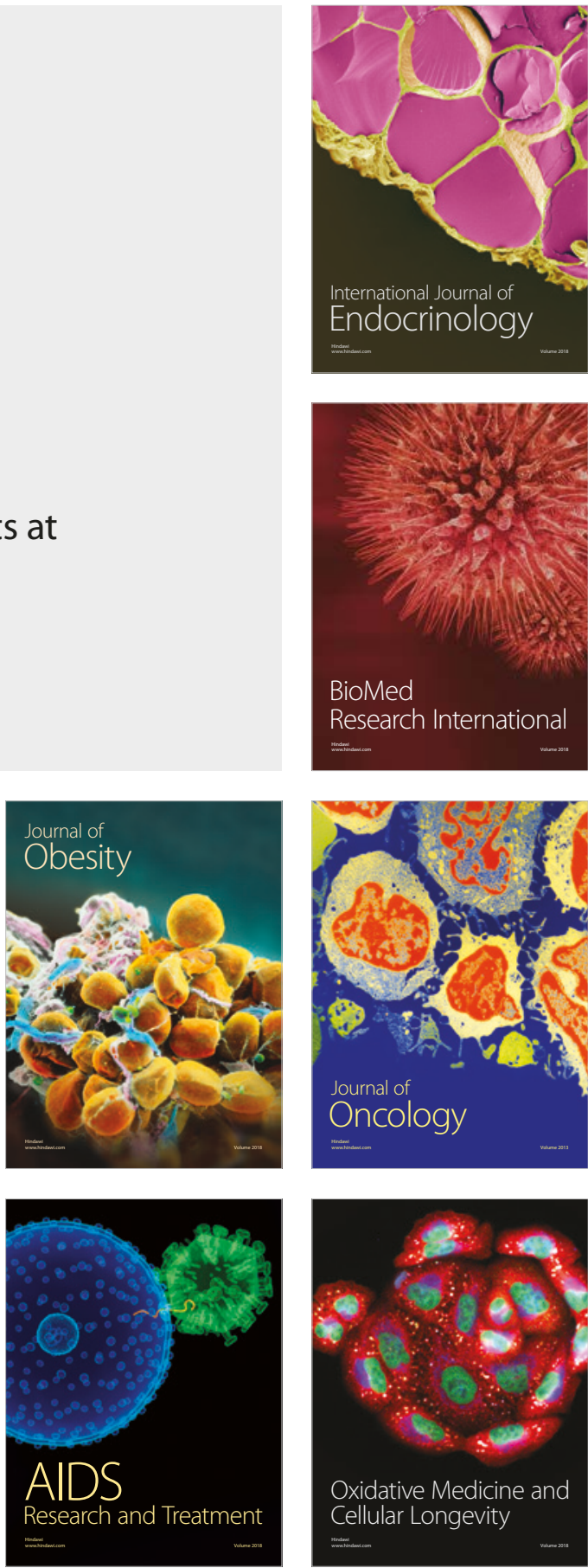